\title{
Diagnosis of urothelial carcinoma from urine
}

\author{
Bernard Têtu \\ Department of Pathology, Centre Hospitalier Universitaire de Québec, L'Hôtel-Dieu de Québec, Laval \\ University, Québec, QC, Canada
}

\begin{abstract}
Urine cytology is the most widely used noninvasive test to detect urothelial tumors. However, it is limited by its low sensitivity. On the other hand, cystoscopy is the gold standard procedure to follow patients with a history of bladder cancer but this test is invasive and costly. Therefore, there is a real need to develop new tests that can be used in bladder cancer surveillance. Several soluble and cell-based markers have been developed and most of them improve the sensitivity of cytology but the specificity is invariably decreased. Of the cell-based tests, two obtained Food and Drug Administration approval. ImmunoCyt/uCyt ${ }^{\mathrm{TM}}$ is a fluorescent test that uses three monoclonal antibodies and UroVysion ${ }^{\mathrm{TM}}$ is an in situ hybridization test, which uses four different probes to different chromosomes. Both tests have a high sensitivity to detect cancer cells and can help to predict urothelial cancer recurrence. ImmunoCyt/uCyt is somewhat better at detecting low-grade tumors but UroVysion is not affected by prior BCG treatment. However, both tests use fluorescent dyes, are time-consuming and require trained personnel. Because of their high negative predictive value, both tests may help the urologist to postpone a number of cystoscopies, especially in patients with low-risk urothelial cancer.

Modern Pathology (2009) 22, S53-S59; doi:10.1038/modpathol.2008.193
\end{abstract}

Keywords: immunocyt; urovysion; urothelial cancer

Bladder cancers limited to the mucosa (Tis, Ta) or invading into the lamina propria (T1), without muscle invasion $^{1}$ represent more than $80 \%$ of urothelial carcinomas and the recurrence rate exceeds $50 \%{ }^{1-3}$ Standard practice in the follow-up of patients with bladder cancer requires cystoscopies (the current 'gold standard') at regular intervals and the schedule is maintained when a recurrence occurs. ${ }^{4}$ As cystoscopy is costly and uncomfortable and that still $10 \%$ of lesions are missed, ${ }^{5}$ there is clearly a need for noninvasive urine markers that would help to reduce the number of cystoscopies.

Cytology is the most widely used noninvasive test. It is very specific but this test is limited by its low sensitivity ranging from 28 to $100 \%$ with a median of $48 \%{ }^{6-8}$ Cytology is most useful at detecting high-grade cancer whereas its sensitivity for low-grade urothelial tumors is low and merely reaches $17 \%{ }^{6}$ in certain studies. Furthermore, criteria used in urinary cytology to detect tumor cells are largely subjective and the ability to detect

Correspondence: Dr B Têtu, MD, Department of Pathology, Centre Hospitalier Universitaire de Québec, L’Hôtel-Dieu de Québec, Laval University, 11, Côte du Palais, Québec, QC, G1R 2J6 Canada.

E-mail: bernard.tetu@chuq.qc.ca

Received 13 October 2008; accepted 19 October 2008 cancer cells is dependent on the experience of cytologists or pathologists. ${ }^{9}$

\section{Screening vs surveillance}

A good marker for clinical use has been defined by the International Bladder Cancer Network as a reliable and consistently measured marker, which possesses a good sensitivity and a good specificity and that use will improve the outcome of the patients. ${ }^{10}$ The choice of a tumor marker depends largely on the clinical needs. A biomarker should be technically simple, reliable and accurate. ${ }^{4}$ However, each marker possesses its own characteristics but none is ideal. There are two major situations, which require somewhat different marker characteristics. The marker may be used for either screening of bladder cancer or for the detection of tumors in patients with symptoms or followed with a history of bladder cancer. If the marker is to be used for screening, it requires a low false-positive rate to avoid unnecessary investigation. Very few markers are sensitive and specific enough to be safely used in a screening program. For patients under surveillance for bladder tumor recurrence, a marker with high sensitivity and high negative predictive value may help to limit the frequency of cystosocopies. ${ }^{4}$ Such a marker with high negative predictive value 
may be useful in patients presenting with either microhematuria and gross hematuria who, respectively, have a 5 and $27 \%$ risk of having bladder cancer. ${ }^{11}$

\section{Most commonly used markers}

A number of noninvasive tests to detect urinary bladder cancer (UBC) have been developed. It is interesting to note that almost all tumor markers have a much better sensitivity than cytology but few reached the same level of specificity. Currently, BTA stat, BTA TRAK, NMP-22, ImmunoCyt/uCyt ${ }^{\mathrm{TM}}$ and UroVysion $^{\text {TM }}$ obtained either Food and Drug Administration (FDA) clearance or approval. ${ }^{7}$

Tumors markers can be divided into two categories based on whether urine (soluble urine markers) or exfoliated cells (cell-associated markers) are used for the assay.

\section{Soluble Urine Markers}

\section{Hematuria detection}

Hematuria is a common finding in patients presenting with urinary tract malignancies. ${ }^{4}$ However, hematuria is also common with inflammatory conditions such as stone disease, benign prostatic hyperplasia and other conditions, which explain specificities as low as $67 \% .^{8}$ The sensitivity of hemoglobin dipstick testing ranges from 46 to $74 \% .{ }^{4}$ It is a useful first-line marker to detect urologic diseases.

\section{BTA stat and BTA TRAK}

BTA stat and BTA TRAK (Bard Diagnostics, Redmond, WA, USA) are antibodies detecting proteins (complement factor H-related protein) present in urine and can be used at a physician's office. ${ }^{6}$ Both are FDA approved. BTA stat is an immunoassay. BTA TRAK is a standard ELISA, which quantitatively measures the amounts of complement factor H-related protein. The sensitivity of both tests ranges from 17 to $89 \%$ and is dependent on tumor grade, stage and size. ${ }^{12-20}$ However, although these tests may improve the sensitivity of cytology, such improvement remains modest for low-grade, lowstage tumors. ${ }^{6}$ Although the specificity reaches $90 \%$ and over in healthy individuals, it is much lower with a variety of benign genitourinary conditions. ${ }^{4}$

\section{$N M P-22$}

NMP-22 (Matritech, Cambridge, MA, USA) is a nuclear matrix protein involved in proper distribution of chromatin during replication. NMP-22 levels are usually low in normal cells whereas they are 25 -fold or greater in patients with bladder cancer. This is a quantitative sandwich ELISA test using two antibodies, which recognize two different epitopes. The sensitivity is around $50-70 \%$ and specificity reaches $60-90 \% .{ }^{17,18,21-24}$ This test is FDA approved for patients with symptoms of bladder cancer or at high risk for. A nomogram has been developed to better predict probability of urothelial cancer recurrence and progression. ${ }^{25}$ However, the reliability of the test is questionable because of the heterogeneity in the diagnostic performance among populations from different institutions. ${ }^{26}$

\section{$B L C A-4$ and BLCA-1}

BLCA-4 and BLCA-1 are nuclear matrix proteins identified by proteomic analyses. Both have a high sensitivity and specificity. The analysis is a sandwich ELISA and uses two monoclonal antibodies. Both are potentially useful markers for the detection of bladder cancer. ${ }^{4}$

\section{HA-HAse}

This ELISA-like test combines the analysis of hyaluronic acid and hyaluronidase. HA-HAse is expressed by tumors and involved in angiogenesis, tumor growth and invasion. The test has a high sensitivity to detect low and high grade and stage tumors. In one study, HA-HAse was reported with very good sensitivity (83\%), specificity (78\%), positive predictive value $(64 \%)$ and negative predictive value $(90 \%) .{ }^{27}$

\section{Survivin}

Survivin is an antiapoptotic protein. The test is being performed by BioDot microfiltration detection system. Limited data published to date show that this is a promising marker with relatively high sensitivity and specificity. ${ }^{4}$

\section{Cell-Based Markers}

Molecular or protein assays

Microsatellite Analysis. Microsatellites are highly polymorphic short tandem DNA repeats (mostly $2-4 \mathrm{bp}$ each) found throughout the genome. Two types of microsatellite alterations are found: (1) loss of heterozygosity (LOH) and (2) microsatellite instability. LOH are often found on chromosome 9. The test is carried out by PCR using DNA primers. This test offers interesting sensitivities (72-97\%) and specificities (80-100\%), ${ }^{4,28}$ but requires expensive equipment and trained personnel.

Telomerase. Telomerase is a ribonucleoprotein that adds telomeres (repetitious sequences that cap the end of chromosomes and maintain genome stability) at the end of the chromosomes and leads to cell immortality. Telomerase can be measured by PCR amplification (TRAP test) or by RT-PCR (hTERT mRNA). The sensitivity is around $70-90 \%$ and the specificity reaches $80-90 \%,, 4,21,29$ although the latter may be lower in inflammatory conditions.

Cytokeratins. These tests take advantage of the differential expression of cytokeratins between benign and malignant cells. Their use is, however, largely limited by their high false-positive rates with 
different clinical disorders. Major tests include the UBC test, which is a sandwich ELISA targeting cytokeratins 8 and 18, the cytokeratin 20 test, which is detected by RT-PCR and CYFRA 21-1, which is an immunoradiometric and electrochemiluminescent assay targeting cytokeratin $19 .^{4}$

\section{Cytologic-based tests}

DD23. DD23 is a monoclonal antibody derived from the immunization of mice with a human bladder specimen and detects a tumor-associated antigen expressed by bladder cancer but not normal urothelial cells. ${ }^{30}$ The sensitivity is around $70 \%$ and the specificity around $60 \%{ }^{30,31}$

Keratins. Keratin 20 by immunocytochemistry provides a sensitivity and a specificity of 65 and $90 \%$, respectively, but the sensitivity is lower for low-grade tumors. ${ }^{32}$

Lewis $X$. This test has a relatively high reported sensitivity (83\%) and specificity (85\%). However, it has rarely been investigated and its expression on umbrella cells may interfere with the results of the assay. $^{7}$

Quanticyt Nuclear Karyometry. This is a quantitative karyometric cytology system measuring nuclear features (nuclear shape and DNA content) in light microscopy images. Sensitivity $(60 \%)$ and specificity $(80 \%)$ are usually regarded as modest. ${ }^{4,7}$

ImmunoCyt/uCyt $t^{\mathrm{TM}}$. ImmunoCyt/uCyt ${ }^{\mathrm{TM}}$ (DiagnoCure Inc., Québec, QC, Canada) has been developed by Fradet and Lockhart and was aimed at improving the low sensitivity of cytology. ${ }^{33}$ It is used as a complement to cytology and can be performed by the same personnel trained for cytology screening. This test obtained FDA clearance in 2000. This fluorescence test combines three monoclonal antibodies. ${ }^{34}$ M344 and LDQ10, labeled with fluorescein, a green fluorescence, have been raised against mucin-like antigens. M344 is expressed by $71 \%$ of Ta-T1 tumors. ${ }^{35}$ 19A211, labeled with Texas red, recognizes a high molecular form of carcinoembryonic antigen and is expressed by $90 \%$ of Ta-T1 tumors. ${ }^{35}$

This test is usually regarded as very promising but needs to be validated in a large-scale prospective multicenter validation study. ${ }^{5}$ Furthermore, although this test cannot be performed in a physician's office, it was not aimed at being performed in large centralized laboratories. Indeed, in most studies, good interobserver concordance was obtained even in smaller laboratories ${ }^{36-38}$ provided that quality control programs are well established. The major disadvantages are that the test is largely operator-dependent and time-consuming and requires at least 500 cells to call a case negative. Furthermore, this test requires on site training, significant experience and regular quality controls by the company. Finally, the use of fluorescence does not allow optimal cytologic evaluation.

Sensitivity of ImmunoCyt/uCyt ${ }^{\mathrm{TM}}$ ranges from 53 to $100 \%$ (average $90 \%$ ) and specificity ranges from 64 to $95 \%(74 \%){ }^{33,34,36,37,39-43}$ A major advantage over other tests is its sensitivity to detect both low-grade and high-grade tumors. Whereas the sensitivity of cytology increased from $8.3 \%$ for grade 1 tumors to $75 \%$ for grade 3 tumors, sensitivity of ImmunoCyt/uCyt ${ }^{\mathrm{TM}}$ reached $79 \%$ for grade $1,84 \%$ for grade 2 and $92 \%$ for grade 3 tumors. ${ }^{44}$ The detection of abnormal cells is relatively easy because fluorescent cells are readily visible even if few events are present and their detection does not rely on subtle subjective morphologic criteria. Therefore, the high sensitivity of ImmunoCyt/uCyt ${ }^{\mathrm{TM}}$ may help pathologists and cytologists to save time at screening slides.

ImmunoCyt/uCyt ${ }^{\mathrm{TM}}$ may also improve the particularly low sensitivity of cytology at detecting upper urinary tract urothelial cell carcinoma. Indeed, whereas no grade 1 tumors and $17 \%$ of grade 2 carcinomas only were detected by cytologic examination in upper urinary tract, the sensitivity raised to $33 \%$ of grade 1 tumors and $100 \%$ of grade 2 carcinomas with ImmunoCyt/uCyt ${ }^{\mathrm{TM}} .^{42}$

The combination of ImmunoCyt/uCyt ${ }^{\mathrm{TM}}$ with cytology may also help to detect nonvisible highgrade cancers, which may be missed by the cystoscopist. In several studies, whereas up to $50 \%$ are either cytologically negative or suspicious, all carcinomas in situ are detected by combining cytology and ImmunoCyt/uCyt ${ }^{\text {TM }}$ 34,36,38,39,45 However, although ImmunoCyt/uCyt ${ }^{\mathrm{TM}}$ is somewhat less sensitive in the follow-up of patients under BCG therapy, the combination with cytology leads to a sensitivity of $100 \%$ for recurrences. ${ }^{46}$

ImmunoCyt/uCyt ${ }^{\mathrm{TM}}$ may also help to predict urothelial tumor recurrence. With a history of urothelial tumor and negative cystoscopy, $18 \%$ of patients with 'false-positive' ImmunoCyt/uCyt ${ }^{\mathrm{TM}}$ developed a recurrence, 2-6 months after the negative cystoscopy, compared to $7 \%$ only in those with negative ImmunoCyt/uCyt ${ }^{\mathrm{TM}} 39$ and $47 \%$ developed a recurrence at 1 year, as opposed to $11.9 \%$ for patients with a negative test. ${ }^{45}$

Multitarget Multicolor Fluorescent In Situ Hybridization Assay Or Multitarget Fluorescence In Situ Hybridization (UroVysion $^{\mathrm{TM}}$ ). The UroVysion ${ }^{\mathrm{TM}}$ test (Abbott Molecular, Des Plaines, IL, USA) is a multitarget multicolor fluorescent in situ hybridization (FISH) assay. This test takes advantage of the high occurrence of specific chromosomal abnormalities in urothelial cancers. ${ }^{4}$ The use of several probes is aimed at improving the sensitivity of single probes. Using paraffin-embedded tissue microarrays, UroVysion ${ }^{\mathrm{TM}}$ showed abnormalities in $93 \%$ of dysplasias, $91 \%$ of CIS and in all invasive cancers whereas they were found in $17 \%$ of urothelial hyperplasia, reactive atypias and normal urothelium of healthy patients and in $30 \%$ of nonneoplastic lesions in patients with concomitant urothelial carcinoma. $^{47}$

The test is being performed on exfoliated cells from urine using centromeric fluorescent denatured chromosome enumeration probes for chromosome 3 
(stratum red), 7 (spectrum green), 17 (spectrum aqua) and the locus-specific identifier probe for 9p21 (spectrum gold), which were found to be most sensitive to detect carcinoma. ${ }^{48}$ No consensus has been reached on the definition of abnormality and several studies ${ }^{4,49-52}$ found significant findings by modifying suggested manufacturer's criteria.

The interpretation of UroVysion ${ }^{\mathrm{TM}}$ may be difficult, in part because of the use of fluorescence. Although polysomy of one or more chromosomes is straightforward if the DAPI stain defines nuclear borders, detection of 9p21 deletion is more difficult if the cell is polysomic, as it is detected relative to the number of other chromosomes. ${ }^{47}$

The sensitivity of UroVysion ${ }^{\mathrm{TM}}$ ranges from $39^{53}$ to $97 \%$ (average $74 \%^{54}$ ) but is significantly lower for low-grade and low-stage tumors. ${ }^{29,53,55}$ The specificity is, however, high (89-100\%), even with a variety of benign genitourinary conditions. ${ }^{29,53,56,57}$ As for any FISH technology, this test is better performed in a reference laboratory and the interpretation is time-consuming. UroVysion ${ }^{\mathrm{TM}}$ was also significantly more sensitive than voided cytology to detect bladder cancer in patients evaluated for gross or microscopic hematuria associated with tumors of any grade and stage. ${ }^{58}$ The detection of upper tract urothelial carcinoma is also improved compared to cytology although tetrasomic an near-tetrasomic tend to be more abundant, more likely because of the abundance of umbrella cells in upper tract washing specimens. ${ }^{59}$

The test was also particularly useful at predicting tumor recurrence. In a population of patients with a history of urothelial carcinoma and negative control cystoscopy, UroVysion ${ }^{\mathrm{TM}}$ predicted a recurrence in $39 \%$ of patients with a positive test and in $21 \%$ of patients with a negative test. ${ }^{49}$ In another study, $27 \%$ of patients under bladder carcinoma surveillance without immediate evidence of tumor recurrence had a positive UroVysion ${ }^{\mathrm{TM}}$ and $65 \%$ of these patients had recurrent urothelial carcinoma within 29 months. ${ }^{60}$ Recurrent tumors also developed in $45 \%$ of patients with abnormal UroVysion ${ }^{\mathrm{TM}}$ test compared to $12.5 \%$ of patients with normal assay. ${ }^{61}$ Furthermore, $85 \%$ of patients with atypical cytology and positive FISH developed a biopsy-proven urothelial carcinoma within 12 months. ${ }^{50}$ Finally, in one study, all patients treated with BCG for superficial bladder cancer and with positive postBCG UroVysion ${ }^{\mathrm{TM}}$ test had tumor recurrence and the risk of progression was ninefold. ${ }^{62}$ Therefore, the sensitivity of UroVysion ${ }^{\mathrm{TM}}$ does not seem to be influenced by prior BCG treatment.

Technical problems are rarely critical with UroVysion $^{\mathrm{TM}}$. However, the presence of too many granulocytes or massive bacteriuria and their association with epithelial cells can obscure the signal. ${ }^{56}$ Furthermore, as for ImmunoCyt/uCyt ${ }^{\mathrm{TM}}$ this test is operator-dependent and time-consuming and the use of fluorescent may obscure cytologic features. ${ }^{56}$
Table 1 Advantages and disadvantages of UroVysion ${ }^{\mathrm{TM}}$ and ImmunoCyt/uCyt ${ }^{\mathrm{TM}}$

$\begin{array}{cc}\text { UroVysion }^{\mathrm{TM}} & \text { Immuno } \\ \text { Cyt/uCyt } & \end{array}$

Advantages

High sensitivity for high grade tumor

High sensitivity for low grade tumor

Detects occult lesions

Predicts recurrence

Not affected by BCG

FDA-approved

Detects upper tract tumor

$\begin{array}{ll}\text { X } & \text { X } \\ & \text { X } \\ \text { X } & \text { X } \\ \text { X } & \text { X } \\ \text { X } & \text { X } \\ \text { X } & \text { X }\end{array}$

Disadvantages

Cytopathologist required

Nonstandard criteria

Time-consuming

Requires fluorescence

Requires 500 cells for negative

Training required

$\begin{array}{ll}\mathrm{X} & \mathrm{X} \\ \mathrm{X} & \\ \mathrm{X} & \mathrm{X} \\ \mathrm{X} & \mathrm{X} \\ & \mathrm{X} \\ \mathrm{X} & \mathrm{X}\end{array}$

$\mathrm{X}$, Feature shared by the marker.

\section{UroVysion $^{\mathrm{TM}}$ vs ImmunoCyt/uCyt ${ }^{\mathrm{TM}}$}

These latter two tests are most popular among pathologists because they are microscope based and are FDA approved. They also share a number of advantages and disadvantages that are outlines in Table 1.

Many studies confirm that most biomarkers significantly improve the sensitivity of cytology. A test with both high sensitivity and negative predictive value may help to reduce the frequency of follow-up cystoscopies. Tests with sensitivities around 90\% and a negative predictive value around $95 \%$ means that, if the test is negative, patients undergoing a standard cystoscopy protocol for a history of bladder cancer are unlikely to have recurrent bladder tumor and that the next control cystoscopy may be safely postponed. In a recent study, from the patient perspective, $75 \%$ would accept the results of a urine test as a replacement for cystoscopy only if it was capable of detecting more than $95 \%$ of recurrent tumor and $21 \%$ more would accept if the test is 90-95\% accurate. ${ }^{63}$ In younger patients investigated for urinary symptoms, presence of a bladder tumor is unlikely with a negative test and cystoscopy might be omitted in certain cases.

For example, in low-risk patients, for whom a lower recurrence and progression rate is expected, ${ }^{64}$ ImmunoCyt/uCyt ${ }^{\mathrm{TM}}$ and cytology every 6 months combined with annual cystoscopy helped to reduce morbidity and cost of follow-up with minimal risk of missing progression. ${ }^{65}$ Flow charts incorporating ImmunoCyt/ $\mathrm{uCyt}^{\mathrm{TM}}$ and UroVysion ${ }^{\mathrm{TM}}$ as parameters to better define the indications to cystoscopy have been developed. ${ }^{44}$ The test was found particularly sensitive and specific in patients with asymptomatic microhematuria and, if such criteria would have been applied to select patients for cystoscopy, $9 \%$ of individuals only would have had an unnecessary procedure. ${ }^{66}$ 
Similarly, no patients with a negative UroVysion ${ }^{\mathrm{TM}}$ test and negative cystoscopy, monitored for urothelial tumor, developed a tumor within 1 year of follow-up. ${ }^{54}$ Only two patients developed a recurrence, 20 and 22 months later. ${ }^{54}$ Therefore, it is suggested by the authors that, in low-risk patients with negative cytology and UroVysion ${ }^{\mathrm{TM}}$ cystoscopy may be postponed by at least 1 year.

Reactive urothelial cells show mild abnormalities that are shared by low-grade neoplastic cells and require considerable screening time from pathologists and cytologists. ${ }^{9}$ The presence of significant abnormalities warrants a diagnosis of atypias suspicious for malignancy. Such diagnosis usually may force the urologist to undertake additional unnecessary investigations. The availability of a complement to cytology for such cases may help to save professional time to both pathologists and urologists.

Of 30 cases with tumor and a suspicious cytology, ImmunoCyt/uCyt ${ }^{\mathrm{TM}}$ was positive in $73 \%$ of cases. Those tumors were not insignificant because $41 \%$ were high-grade carcinomas. ${ }^{39}$ The sensitivity for UroVysion $^{\text {TM }}$ on patients with biopsy-proven urothelial carcinoma and cytology interpreted as suspicious, atypical and negative was 100, 89 and $60 \%$, respectively. ${ }^{50}$

In conclusion, several new tests have been developed to improve the sensitivity of cytology. Of them, cell-based tests are particularly attractive for pathologists because they allow cell visualization. ImmunoCyt/uCyt ${ }^{\mathrm{TM}}$ and UroVysion ${ }^{\mathrm{TM}}$ are currently the most common commercial markers used in a clinical setting and share a number of common characteristics. Future studies should evaluate the influence of those markers on the frequency of follow-up cystoscopies.

\section{Disclosure/conflict of interest}

Dr Têtu is consultant for DiagnoCure Inc., which developed the ImmunoCyt/uCyt + test.

\section{References}

1 Koch M, Hill GB, McPhee MS. Factors affecting recurrence rates in superficial bladder cancer. J Natl Cancer Inst 1986;76:1025-1029.

2 Malmstrom PU, Busch C, Norlen BJ. Recurrence, progression and survival in bladder cancer. A retrospective analysis of 232 patients with greater than or equal to 5-year follow-up. Scand J Urol Nephrol 1987;21:185-195.

3 Stein JP, Grossfeld GD, Ginsberg DA, et al. Prognostic markers in bladder cancer: a contemporary review of the literature. J Urol 1998;160:645-659.

4 Lokeshwar VB, Habuchi T, Grossman HB, et al. Bladder tumor markers beyond cytology: International Consensus Panel on bladder tumor markers. Urology 2005;66:35-63.
5 Black PC, Brown GA, Dinney CP. Molecular markers of urothelial cancer and their use in the monitoring of superficial urothelial cancer. J Clin Oncol 2006;24:5528-5535.

6 Lokeshwar VB, Soloway MS. Current bladder tumor tests: does their projected utility fulfill clinical necessity? J Urol 2001;165:1067-1077.

7 van Rhijn BW, van der Poel HG, van der Kwast TH. Urine markers for bladder cancer surveillance: a systematic review. Eur Urol 2005;47:736-748.

8 Konety BR. Molecular markers in bladder cancer: a critical appraisal. Urol Oncol 2006;24:326-337.

9 Murphy WM. Current status of urinary cytology in the evaluation of bladder neoplasms. Hum Pathol 1990;21:886-896.

10 Goebell PJ, Groshen SL, Schmitz-Drager BJ. Guidelines for development of diagnostic markers in bladder cancer. World J Urol 2008;26:5-11.

11 Schmitz-Drager BJ, Tirsar LA, Schmitz-Drager C, et al. Immunocytology in the assessment of patients with asymptomatic hematuria. World J Urol 2008;26:31-37.

12 Mian C, Lodde M, Haitel A, et al. Comparison of two qualitative assays, the UBC rapid test and the BTA stat test, in the diagnosis of urothelial cell carcinoma of the bladder. Urology 2000;56:228-231.

13 Sarosdy MF, Hudson MA, Ellis WJ, et al. Improved detection of recurrent bladder cancer using the Bard BTA stat Test. Urology 1997;50:349-353.

14 Gutierrez Banos JL, Henar Rebollo RM, Antolin Juarez FM, et al. Usefulness of the BTA STAT test for the diagnosis of bladder cancer. Urology 2001;57:685-689.

15 Leyh H, Hall R, Mazeman E, et al. Comparison of the Bard BTA test with voided urine and bladder wash cytology in the diagnosis and management of cancer of the bladder. Urology 1997;50:49-53.

16 Irani J, Desgrandchamps F, Millet C, et al. BTA stat and BTA TRAK: a comparative evaluation of urine testing for the diagnosis of transitional cell carcinoma of the bladder. Eur Urol 1999;35:89-92.

17 Serretta V, Pomara G, Rizzo I, et al. Urinary BTA-stat, BTA-trak and NMP22 in surveillance after TUR of recurrent superficial transitional cell carcinoma of the bladder. Eur Urol 2000;38:419-425.

18 Giannopoulos A, Manousakas T, Mitropoulos D, et al. Comparative evaluation of the BTAstat test, NMP22, and voided urine cytology in the detection of primary and recurrent bladder tumors. Urology 2000;55:871-875.

19 Chautard D, Daver A, Bocquillon V, et al. Comparison of the Bard Trak test with voided urine cytology in the diagnosis and follow-up of bladder tumors. Eur Urol 2000;38:686-690.

20 Ellis WJ, Blumenstein BA, Ishak LM, et al. Clinical evaluation of the BTA TRAK assay and comparison to voided urine cytology and the Bard BTA test in patients with recurrent bladder tumors. The Multi Center Study Group. Urology 1997;50:882-887.

21 Ramakumar S, Bhuiyan J, Besse JA, et al. Comparison of screening methods in the detection of bladder cancer. J Urol 1999;161:388-394.

22 Lahme S, Bichler KH, Feil G, et al. Comparison of cytology and nuclear matrix protein 22 for the detection and follow-up of bladder cancer. Urol Int 2001;66:72-77.

23 Stampfer DS, Carpinito GA, Rodriguez-Villanueva J, et al. Evaluation of NMP22 in the detection of transitional cell carcinoma of the bladder. J Urol 1998;159:394-398. 
24 Grossman HB, Soloway M, Messing E, et al. Surveillance for recurrent bladder cancer using a point-of-care proteomic assay. JAMA 2006;295:299-305.

25 Shariat SF, Zippe C, Ludecke G, et al. Nomograms including nuclear matrix protein 22 for prediction of disease recurrence and progression in patients with Ta, T1 or CIS transitional cell carcinoma of the bladder. J Urol 2005;173:1518-1525.

26 Shariat SF, Marberger MJ, Lotan Y, et al. Variability in the performance of nuclear matrix protein 22 for the detection of bladder cancer. J Urol 2006;176: 919-926.

27 Hautmann S, Toma M, Lorenzo Gomez MF, et al. Immunocyt and the HA-HAase urine tests for the detection of bladder cancer: a side-by-side comparison. Eur Urol 2004;46:466-471.

28 van Rhijn BW, Lurkin I, Kirkels WJ, et al. Microsatellite analysis-DNA test in urine competes with cystoscopy in follow-up of superficial bladder carcinoma: a phase II trial. Cancer 2001;92:768-775.

29 Halling KC, King W, Sokolova IA, et al. A comparison of BTA stat, hemoglobin dipstick, telomerase and Vysis UroVysion assays for the detection of urothelial carcinoma in urine. J Urol 2002;167:2001-2006.

30 Gilbert SM, Veltri RW, Sawczuk A, et al. Evaluation of DD23 as a marker for detection of recurrent transitional cell carcinoma of the bladder in patients with a history of bladder cancer. Urology 2003;61:539-543.

31 Sawczuk IS, Pickens CL, Vasa UR, et al. DD23 biomarker: a prospective clinical assessment in routine urinary cytology specimens from patients being monitored for TCC. Urol Oncol 2002;7:185-190.

32 Melissourgos ND, Kastrinakis NG, Skolarikos A, et al. Cytokeratin-20 immunocytology in voided urine exhibits greater sensitivity and reliability than standard cytology in the diagnosis of transitional cell carcinoma of the bladder. Urology 2005;66:536-541.

33 Fradet Y, Lockhart C, The Immunocyt Trialists. Performance characteristics of a new monoclonal antibody test for bladder cancer: Immunocyt ${ }^{\mathrm{TM}}$. Can J Urol 1997;4:400-405.

34 Mian C, Pycha A, Wiener H, et al. Immunocyt: a new tool for detecting transitional cell cancer of the urinary tract. J Urol 1999;161:1486-1489.

35 Allard P, Fradet Y, Têtu B, et al. Tumor-associated antigens as prognostic factors for recurrence in 382 patients with primary transitional cell carcinoma of the bladder. Clin Cancer Res 1995;1:1195-1202.

36 Messing EM, Teot L, Korman H, et al. Performance of urine test in patients monitored for recurrence of bladder cancer: a multicenter study in the United States. J Urol 2005;174:1238-1241.

37 Olsson H, Zackrisson B. ImmunoCyt a useful method in the follow-up protocol for patients with urinary bladder carcinoma. Scand J Urol Nephrol 2001;35: 280-282.

38 Pfister C, Chautard D, Devonec M, et al. Immunocyt test improves the diagnostic accuracy of urinary cytology: results of a French multicenter study. J Urol 2003;169:921-924.

39 Têtu B, Tiguert R, Harel F, et al. ImmunoCyt/uCyt+ improves the sensitivity of urine cytology in patients followed for urothelial carcinoma. Mod Pathol 2005;18:83-89.

40 Lodde M, Mian C, Negri G, et al. Effect of intravesical instillation on performance of uCYT+ test. Urology 2004;63:878-881.
41 Vriesema JL, Atsma F, Kiemeney LA, et al. Diagnostic efficacy of the ImmunoCyt test to detect superficial bladder cancer recurrence. Urology 2001;58:367-371.

42 Lodde M, Mian C, Wiener H, et al. Detection of upper urinary tract transitional cell carcinoma with ImmunoCyt: a preliminary report. Urology 2001;58:362-366.

43 Lodde M, Mian C, Negri G, et al. Role of uCyt+ in the detection and surveillance of urothelial carcinoma. Urology 2003;61:243-247.

44 Mian C, Maier K, Comploj E, et al. uCyt+/ImmunoCyt in the detection of recurrent urothelial carcinoma: an update on 1991 analyses. Cancer 2006;108:60-65.

45 Piaton E, Daniel L, Verriele V, et al. Improved detection of urothelial carcinomas with fluorescence immunocytochemistry (uCyt+ assay) and urinary cytology: results of a French Prospective Multicenter Study. Lab Invest 2003;83:845-852.

46 Mian C, Lodde M, Comploj E, et al. The value of the ImmunoCyt/uCyt+ test in the detection and follow-up of carcinoma in situ of the urinary bladder. Anticancer Res 2005;25:3641-3644.

47 Schwarz S, Rechenmacher M, Filbeck T, et al. Value of multicolor fluorescence in situ hybridization (UroVysion-TM) in the differential diagnosis of flat urothelial lesions. J Clin Pathol 2007;61:272-277.

48 Sokolova IA, Halling KC, Jenkins RB, et al. The development of a multitarget, multicolor fluorescence in situ hybridization assay for the detection of urothelial carcinoma in urine. J Mol Diagn 2000;2:116-123.

49 Zellweger T, Benz G, Cathomas G, et al. Multi-target fluorescence in situ hybridization in bladder washings for prediction of recurrent bladder cancer. Int J Cancer 2006;119:1660-1665.

50 Skacel M, Fahmy M, Brainard JA, et al. Multitarget fluorescence in situ hybridization assay detects transitional cell carcinoma in the majority of patients with bladder cancer and atypical or negative urine cytology. J Urol 2003;169:2101-2105.

51 Bubendorf L, Grilli B, Sauter G, et al. Multiprobe FISH for enhanced detection of bladder cancer in voided urine specimens and bladder washings. Am J Clin Pathol 2001;116:79-86.

52 Varella-Garcia M, Akduman B, Sunpaweravong P, et al. The UroVysion fluorescence in situ hybridization assay is an effective tool for monitoring recurrence of bladder cancer. Urol Oncol 2004;22:16-19.

53 Moonen PM, Merkx GF, Peelen P, et al. UroVysion compared with cytology and quantitative cytology in the surveillance of non-muscle-invasive bladder cancer. Eur Urol 2007;51:1275-1280.

54 Daniely M, Rona R, Kaplan T, et al. Combined morphologic and fluorescence in situ hybridization analysis of voided urine samples for the detection and follow-up of bladder cancer in patients with benign urine cytology. Cancer 2007;111:517-524.

55 Laudadio J, Keane TE, Reeves HM, et al. Fluorescence in situ hybridization for detecting transitional cell carcinoma: implications for clinical practice. BJU Int 2005;96:1280-1285.

56 Riesz P, Lotz G, Paska C, et al. Detection of bladder cancer from the urine using fluorescence in situ hybridization technique. Pathol Oncol Res 2007;13:187-194.

57 Mian C, Lodde M, Comploj E, et al. Liquid-based cytology as a tool for the performance of uCyt+ and UroVysion multicolour-FISH in the detection of urothelial carcinoma. Cytopathology 2003;14:338-342. 
58 Sarosdy MF, Kahn PR, Ziffer MD, et al. Use of a multitarget fluorescence in situ hybridization assay to diagnose bladder cancer in patients with hematuria. J Urol 2006;176:44-47.

59 Halling KC, Kipp BR. Bladder cancer detection using FISH (UroVysion assay). Adv Anat Pathol 2008;15:279-286.

60 Yoder BJ, Skacel M, Hedgepeth R, et al. Reflex UroVysion testing of bladder cancer surveillance patients with equivocal or negative urine cytology: a prospective study with focus on the natural history of anticipatory positive findings. Am J Clin Pathol 2007;127:295-301.

61 Gofrit ON, Zorn KC, Silvestre J, et al. The predictive value of multi-targeted fluorescent in-situ hybridization in patients with history of bladder cancer. Urol Oncol 2008;26:246-249.
62 Kipp BR, Karnes RJ, Brankley SM, et al. Monitoring intravesical therapy for superficial bladder cancer using fluorescence in situ hybridization. J Urol 2005;173:401-404.

63 Yossepowitch O, Herr HW, Donat SM. Use of urinary biomarkers for bladder cancer surveillance: patient perspectives. J Urol 2007;177:1277-1282.

64 Allard P, Bernard P, Fradet Y, et al. The early clinical course of primary $\mathrm{Ta}$ and $\mathrm{T} 1$ bladder cancer: a proposed prognostic index. Br J Urol 1998;81:692-698.

65 Lodde M, Mian C, Comploj E, et al. uCyt+ test: alternative to cystoscopy for less-invasive follow-up of patients with low risk of urothelial carcinoma Urology 2006;67:950-954.

66 Schmitz-Drager BJ, Beiche B, Tirsar LA, et al. Immunocytology in the assessment of patients with asymptomatic microhaematuria. Eur Urol 2007;51:1582-1588. 